\title{
AMBIENTES DE OCORRÊNCIA NATURAL DE MACAÚBA ${ }^{1}$
}

\author{
Héria de Freitas Teles ${ }^{2}$, Larissa Leandro Pires², José Garcia ${ }^{2}$, \\ Juliano Queiroz Santana Rosa², João Gaspar Farias², Ronaldo Veloso Naves ${ }^{2}$
}

\section{ABSTRACT \\ ENVIRONMENTS WITH NATURAL \\ OCCURRENCE OF Acrocomia aculeata}

Acrocomia aculeata, a palm tree common in the Brazilian Savannah region, has been increasingly drawing attention for its high fruit yield and several uses, such as food for humans, fodder, and oil source. The objective of this research was to characterize natural $A$. aculeata environments in the central and southern Goiás State, Brazil. Ten areas, in seven municipalities (Santa Cruz de Goiás, São Miguel do Passa Quatro, São Francisco de Goiás, Paraúna, Jandaia, Indiara, and Jaraguá), were selected. Soil samples made up of ten subsamples were used for chemical and physical characterization of each area, and toposequences were briefly described and classified. Climatic data were obtained from the National Institute of Meteorology through climate normals. Descriptive statistics and correlations among soil fertility variables were calculated. Data showed that $A$. aculeata occurs in soils with more than $50 \%$ of base saturation, considered eutrophic, with medium to high fertility and high potassium levels. Its populations are present in areas with total annual rainfall of 1,300-1,700 mm and corrected annual average air temperature of $21.5-22.5^{\circ} \mathrm{C}$. Areas with a predominance of cambisols and neosols, with medium texture and in the convex slope, talus, and concave slope of the landscape presented higher plant density.

KEY-WORDS: Acrocomia aculeata; Arecaceae; climate; fertility; soil.

\section{INTRODUÇÃO}

A macaúba (Acrocomia aculeata (Jacq.) Lodd. ex Mart.), pertencente à família Arecaceae, é uma palmeira arborescente e nativa de florestas tropicais. Em meio às suas várias utilidades, são relatados usos medicinais, alimentícios e cosméticos (Nucci 2007). Alguns estudos comprovam, também, que esta planta, até então pouco estudada e quase desconhecida, tem futuro promissor na produção

\section{RESUMO}

A macaúba (Acrocomia aculeata), palmeira presente na região do Cerrado, tem despertado grande interesse, pela produção de frutos e sua utilidade alimentícia, forrageira e oleaginosa. Este trabalho objetivou caracterizar ambientes de ocorrência natural de macaúba, nas regiões centro e sul do Estado de Goiás. Para o estudo, selecionaram-se dez áreas, em sete municípios (Santa Cruz de Goiás, São Miguel do Passa Quatro, São Francisco de Goiás, Paraúna, Jandaia, Indiara e Jaraguá). Para a caracterização química e física do solo, trabalhou-se com uma amostra composta por dez subamostras por área, além da descrição da topossequência e de classificação sucinta. Os dados climáticos foram obtidos por meio das normais climatológicas do Instituto Nacional de Meteorologia. Foram realizadas análises estatísticas descritivas e correlações entre os dados de fertilidade do solo. De acordo com os resultados, a macaúba se desenvolve em solos com mais de $50 \%$ de saturação por bases, considerados eutróficos, de média a alta fertilidade e altos níveis de potássio. Populações da espécie ocorrem em áreas com precipitação total anual de $1.300-1.700 \mathrm{~mm}$ e temperatura média do ar anual corrigida de $21,5-22,5^{\circ} \mathrm{C}$. Áreas com predomínio de cambissolos e neossolos, com textura média, e as porções do declive convexo, tálus e declive côncavo da topossequência apresentam maior densidade de plantas.

PALAVRAS-CHAVE: Acrocomia aculeata; Arecaceae; clima; fertilidade; solo.

de biocombustível, óleos para fins alimentícios e na área oleoquímica (Pereira 1996, Aristone \& Oliveira 2004, Nucci 2007). Segundo Nucci (2007), a produção total de óleo dela proveniente pode atingir $4.000 \mathrm{~L} \mathrm{ha}^{-1} \mathrm{ano}^{-1}$, o que tem gerado grande interesse socioeconômico, por parte dos mercados nacional e internacional. O produto apresenta alta qualidade e valores nutricionais próximos aos do azeite de oliva, sendo, hoje, foco, também, de indústrias de cosméticos e alimentos. 
Além de seus diferentes usos e potenciais para exploração, a espécie apresenta ampla distribuição geográfica (Scariot et al. 1995), ocorrendo na América tropical e subtropical, desde o sul do México e Antilhas até o sul do Brasil, chegando ao Paraguai e Argentina (Henderson et al. 1995). No Paraguai, Argentina, Bolívia, sul do Brasil, Mato Grosso do Sul, Mato Grosso, Minas Gerais (Markley 1956, Wandeck \& Justo 1988) e Ceará (Scariot et al. 1995), existem relatos de grandes populações, apontadas como economicamente promissoras.

No Brasil, Silva et al. (1986) enfatizam a importância destes extensos palmares, em várias regiões, como verdadeiro patrimônio em estado potencial, à espera de exploração agrícola-industrial bem orientada. Imensas reservas naturais de palmáceas, como a macaúba, apresentam-se muito promissoras, pelo alto rendimento energético. Contudo, a exploração hoje existente é, basicamente, feita de forma extrativista e com baixa produtividade, já que a instalação de lavouras comerciais enfrenta uma série de dificuldades, incluindo o desconhecimento de suas exigências ecológicas.

De acordo com Novaes (1952), a macaúba é adaptada a solos pobres cobertos por Cerrados, no Estado de São Paulo. Por outro lado, Rocha (1946), Lorenzi (1992) e Motta et al. (2002) relatam sua preferência por solos férteis. Motta et al. (2002), relacionando a ocorrência da macaúba em Minas Gerais a atributos climáticos, pedológicos e vegetacionais, observaram que, além de áreas de solos com fertilidade natural mais elevada, a planta acompanhava vegetação primitiva de fisionomia florestal, mostrando seu avanço como pioneira, evitando extremos de deficiência de nutrientes e de água.

Há necessidade de se estudar e conhecer o ambiente de ocorrência da espécie, tanto para seu uso comercial racional como para sua preservação, tendo-se em vista, ainda, a diversidade de solos e climas existentes no País, nos quais a macaúba pode estar presente. Assim, este trabalho objetivou caracterizar ambientes de ocorrência natural de macaúba, nas regiões centro e sul do Estado de Goiás.

\section{MATERIAL E MÉTODOS}

O trabalho foi realizado de agosto a dezembro de 2007, nas regiões centro e sul do Estado de Goiás, selecionando-se dez áreas no entorno de $200 \mathrm{~km}$ da capital, Goiânia, pela facilidade de deslocamento.
Considerou-se, como critério de seleção, a ocorrência natural da espécie em pastagem e/ou Cerrado, vegetando em quantidade igual ou superior a cinquenta indivíduos adultos agrupados.

As áreas localizavam-se em sete municípios: Santa Cruz de Goiás, São Miguel do Passa Quatro, São Francisco de Goiás, Paraúna, Jandaia, Indiara e Jaraguá. Em Jaraguá, foram selecionadas quatro áreas, devido à alta densidade da palmeira. Nas demais localidades, escolheu-se uma única área por município. Aárea foi demarcada em quatro pontos extremos, com o equipamento de Sistema de Posicionamento Global (GPS), modelo Geo Explorer, determinando-se suas coordenadas geográficas (latitude, longitude e altitude). As latitudes e longitudes foram utilizadas para cálculo da dimensão da área (ha), por meio do programa GPS TrackMaker. Com as altitudes dos pontos, calculou-se a altitude média da área.

Foram coletadas informações sobre as plantas de macaúba, acesso ao local, histórico da área e de seus arredores e a ocorrência de outras espécies vegetais presentes.

Com o auxílio de consulta aos mapas temáticos gerados para o Estado de Goiás, por Lobato et al. (2002), com base nas normais climatológicas do Instituto Nacional de Meteorologia, foram obtidos os dados anuais de precipitação pluvial $(\mathrm{mm})$, umidade relativa (\%), insolação ( $\mathrm{n}^{\mathrm{o}}$ de horas), nebulosidade (décimos de céu aberto), pressão atmosférica (milibares), temperaturas médias, máxima e mínima $\left({ }^{\circ} \mathrm{C}\right)$ e evaporação (mm).

Para a caracterização dos solos, coletou-se uma amostra composta, por área, na camada $0-20 \mathrm{~cm}$ de profundidade, com o auxílio de trado holandês, proveniente de dez subamostras, espacialmente bem distribuídas, cujos pontos de coleta foram sorteados. Determinaram-se os teores dos macronutrientes fósforo (Mehlich I), potássio, cálcio e magnésio, além da matéria orgânica, $\mathrm{pH}$ em $\mathrm{CaCl}_{2}$, alumínio e acidez potencial $(\mathrm{H}+\mathrm{Al})$. Os micronutrientes cobre, ferro, manganês e zinco foram extraídos pelo método de Mehlich I. Foram calculadas, também, a saturação por bases (V\%) e a capacidade de troca de cátions (CTC) total. As determinações analíticas foram obtidas segundo as marchas de extração e determinação propostas pela Embrapa (1997), sendo a de textura realizada por meio da dispersão das partículas do solo com hidróxido de sódio $(\mathrm{NaOH})$ e determinada por meio de densímetro, de acordo com Embrapa (1997). 
Para a caracterização geomorfológica, fez-se a descrição da topossequência e classificação sucinta dos solos da área, observando-se tipo de solo, presença ou não de concreções ou cascalhos e relevo. Posteriormente, foram obtidos o matiz, valor e intensidade de cor do solo, segundo metodologias propostas pela Embrapa (1999).

Foram realizadas análises estatísticas descritivas, observando-se valores mínimos, máximos e médias das variáveis de solo analisadas.

\section{RESULTADOS E DISCUSSÃO}

As áreas encontravam-se com cobertura vegetal predominante de Brachiaria brizantha (A. Rich.) Stapf., ocorrendo, ainda, B. decumbens Stapf., Panicum maximum Jacq. e Andropogon gayanus Kunth., estando cultivadas com pastagens, para a criação de bovinos, há, aproximadamente, 15 anos. Em outros Estados do Brasil, também tem sido observada a ocorrência de macaubais em áreas de pastagens, como descrito por Novaes (1952), para o Estado de São Paulo, o qual também cita a dificuldade de se encontrarem indivíduos nos remanescentes de mata nativa.

Nas áreas estudadas, verificou-se forte pressão antrópica, tendo-se em vista que estas já não possuíam Cerrado remanescente significativo, além da presença de macaubeiras mortas e poucas plantas jovens, na maioria dos locais. A ocorrência de outros vegetais nas áreas não foi tão expressiva, em termos de quantidade, devido ao fato de estas estarem predominantemente cobertas com pastagens. Porém, observou-se a presença de espécies como baru (Dipteryx alata Vogel), lobeira (Solanum lycocarpum A. St.-Hil.), pequi (Caryocar brasiliense Cambess.) e guariroba (Syagrus oleracea Becc.), dentre outras.
Em relação às altitudes médias (Tabela 1), somente a área 8 (Jandaia) apresentou-se abaixo de $600 \mathrm{~m}$, sendo que as demais (90\% das áreas) encontravam-se em altitudes variando de $600 \mathrm{~m}$ a até quase $800 \mathrm{~m}$, apesar de existir referência indicando que a macaúba pode ocorrer em altitudes de até $950 \mathrm{~m}$, no Estado de Minas Gerais (Motta et al. 2002).

As áreas não apresentaram grandes variações, quanto às variáveis climáticas. A temperatura média do ar anual corrigida situou-se entre $21,5^{\circ} \mathrm{C}$ e $22,5^{\circ} \mathrm{C}$, estando a máxima em torno de $29,7^{\circ} \mathrm{C}$ e a mínima entre $17,5^{\circ} \mathrm{C}$ e $20,5^{\circ} \mathrm{C}$. A precipitação total anual variou de $1.300 \mathrm{~mm}$ a $1.700 \mathrm{~mm}$, com $50 \%$ das áreas com mais de $1.600 \mathrm{~mm}$ anuais (Tabela 2). Esta faixa está acima dos valores encontrados por Motta et al. (2002) (1.100-1.500 mm), em algumas regiões de ocorrência de macaúba em Minas Gerais. Contudo, condiz com a apontada por Prates et al. (1986), para a família Arecaceae, associada a ambientes florestais com precipitações entre $1.500 \mathrm{~mm}$ e $2.000 \mathrm{~mm}$. Como ocorre baixa tolerância das palmeiras ao excesso de umidade no solo, parece existir, também, uma faixa estreita de umidade adequada, não só para a macaúba, como, também, para outras espécies (Motta et al. 2002).

Solos com a presença de macaúba apresentaram, em média, $358 \mathrm{~g} \mathrm{dm}^{-3}$ de argila, $186 \mathrm{~g} \mathrm{dm}^{-3} \mathrm{de}$ silte e $456 \mathrm{~g} \mathrm{dm}^{-3} \mathrm{de}$ areia, indicando textura média a argilosa, com alta permeabilidade. As áreas 2 e 6 evidenciaram textura mais argilosa e os menores teores de areia, em comparação com as demais. Diferentemente, a área 8 apresentou solo mais arenoso e menor teor de argila (Tabela 3 ).

$\mathrm{Na}$ região dos topos da topossequência, foram encontrados Latossolos Vermelho e Vermelho-escuro e cambissolos e neossolos, em menor proporção. Nas porções tálus e nos declives, houve predomínio de Neossolos litólicos e regolíticos e de cambissolos,

Tabela 1. Caracterização das áreas com macaúba, nas regiões centro e sul do Estado de Goiás (2007).

\begin{tabular}{|c|c|c|c|c|c|}
\hline \multirow{2}{*}{ Área } & \multirow{2}{*}{ Município } & \multirow{2}{*}{$\begin{array}{c}\text { Dimensão } \\
\text { ha }\end{array}$} & \multirow{2}{*}{ Latitude S } & \multirow{2}{*}{ Longitude $\mathrm{O}$} & Altitude \\
\hline & & & & & $\mathrm{m}$ \\
\hline 1 & Santa Cruz de Goiás & 6,89 & $17^{\circ} 17^{\prime} 32^{\prime \prime}$ & $48^{\circ} 31^{\prime} 40^{\prime \prime}$ & 693 \\
\hline 2 & São Miguel do Passa Quatro & 4,95 & $17^{\circ} 03^{\prime} 12^{\prime \prime}$ & $48^{\circ} 40^{\prime} 41^{\prime \prime}$ & 770 \\
\hline 3 & São Francisco de Goiás & 37,98 & $15^{\circ} 53^{\prime} 11^{\prime \prime}$ & $49^{\circ} 14^{\prime} 28^{\prime \prime}$ & 704 \\
\hline 4 & Jaraguá & 20,95 & $15^{\circ} 35^{\prime} 42^{\prime \prime}$ & $49^{\circ} 17^{\prime} 30^{\prime \prime}$ & 794 \\
\hline 5 & Jaraguá & 24,58 & $15^{\circ} 43^{\prime} 13^{\prime \prime}$ & $49^{\circ} 24^{\prime} 46^{\prime \prime}$ & 680 \\
\hline 6 & Jaraguá & 10,60 & $15^{\circ} 44^{\prime} 10^{\prime \prime}$ & $49^{\circ} 22^{\prime} 26^{\prime \prime}$ & 675 \\
\hline 7 & Paraúna & 4,99 & $16^{\circ} 57^{\prime} 08^{\prime \prime}$ & $50^{\circ} 28^{\prime} 51^{\prime \prime}$ & 749 \\
\hline 8 & Jandaia & 1,76 & $17^{\circ} 02^{\prime} 12^{\prime \prime}$ & $50^{\circ} 08^{\prime} 50^{\prime \prime}$ & 590 \\
\hline 9 & Jaraguá & 7,68 & $15^{\circ} 43^{\prime} 42^{\prime \prime}$ & $49^{\circ} 19^{\prime} 26^{\prime \prime}$ & 615 \\
\hline 10 & Indiara & 10,64 & $17^{\circ} 04^{\prime} 51^{\prime \prime}$ & $49^{\circ} 50^{\prime} 30^{\prime \prime}$ & 655 \\
\hline
\end{tabular}


Tabela 2. Valores médios anuais de dados climáticos das áreas com macaúba, nas regiões centro e sul do Estado de Goiás, segundo Lobato et al. (2002).

\begin{tabular}{|c|c|c|c|c|c|c|c|c|c|c|}
\hline Dados climáticos & Área $1^{*}$ & Área 2 & Área 3 & Área 4 & Área 5 & Área 6 & Área 7 & Área 8 & Área 9 & Área 10 \\
\hline Temperatura do $\operatorname{ar}\left({ }^{\circ} \mathrm{C}\right)$ & 21,5 & 21,5 & 22,5 & 22,5 & 22,5 & 22,5 & 22,5 & 22,5 & 22,5 & 22,5 \\
\hline Temperatura máxima $\left({ }^{\circ} \mathrm{C}\right)$ & 29,7 & 29,7 & 29,7 & 29,7 & 29,7 & 29,7 & 29,7 & 29,7 & 29,7 & 29,7 \\
\hline Temperatura mínima $\left({ }^{\circ} \mathrm{C}\right)$ & 18,5 & 20,5 & 17,5 & 17,5 & 17,5 & 17,5 & 17,5 & 17,5 & 17,5 & 18,5 \\
\hline Precipitação pluvial (mm) & 1.500 & 1.500 & 1.700 & 1.700 & 1.700 & 1.700 & 1.300 & 1.300 & 1.700 & 1.300 \\
\hline Umidade relativa $(\%)$ & 64,5 & 67,5 & 70,5 & 70,5 & 70,5 & 70,5 & 67,5 & 67,5 & 70,5 & 67,5 \\
\hline Insolação (nº de horas) & 2.466 & 2.322 & 2.466 & 2.466 & 2.466 & 2.466 & 2.466 & 2.322 & 2.466 & 2.322 \\
\hline Nebulosidade (décimos de céu aberto) & 5,1 & 5,3 & 5,6 & 5,6 & 5,6 & 5,6 & 5,3 & 5,3 & 5,6 & 5,3 \\
\hline Pressão atmosférica (milibares) & 925 & 925 & 925 & 925 & 925 & 925 & 925 & 925 & 925 & 925 \\
\hline Evaporação (mm) & 1.650 & 1.350 & 2.250 & 2.250 & 2.250 & 2.250 & 1.350 & 1.350 & 2.250 & 1.350 \\
\hline
\end{tabular}

* 1 - Santa Cruz de Goiás; 2 - São Miguel do Passa Quatro; 3 - São Francisco de Goiás; 4, 5, 6 e 9 - Jaraguá; 7 - Paraúna; 8 - Jandaia; 10 - Indiara.

Tabela 3. Análise textural do solo, na camada $0-20 \mathrm{~cm}$, em áreas de ocorrência natural de macaúba, nas regiões centro e sul de Goiás (2007).

\begin{tabular}{ccccc}
\hline \multirow{2}{*}{ Área* } & Argila & Silte & Areia & \multirow{2}{*}{ Classe textural } \\
\cline { 2 - 4 } & \multicolumn{3}{c}{$\mathrm{g} \mathrm{dm}^{-3}$} & \multicolumn{2}{c}{} & \\
\cline { 2 - 4 } 1 & 330 & 230 & 440 & Média \\
2 & 450 & 180 & 370 & Argilosa \\
3 & 350 & 250 & 400 & Média \\
4 & 320 & 150 & 530 & Média \\
5 & 330 & 250 & 420 & Média \\
6 & 450 & 180 & 370 & Argilosa \\
7 & 380 & 130 & 490 & Argilosa \\
8 & 290 & 110 & 600 & Média \\
9 & 380 & 240 & 380 & Argilosa \\
10 & 300 & 140 & 560 & Média \\
\hline Média & 358 & 186 & 456 & - \\
CV (\%) & 15,8 & 28,6 & 18,4 & - \\
\hline * 1 - Santa Cruz de Goiás; 2 - São Miguel do Passa Quatro; 3 - São Francisco de \\
Goiás; 4, 5, 6 e 9 - Jaraguá; 7 - Paraúna; 8 - Jandaia; 10 - Indiara.
\end{tabular}

sendo, também, encontrados latossolos, enquanto, nos pedimentos, foram encontrados solos hidromórficos.

Em vários locais, foram nítidas as pontuações de óxido de ferro e concreções no perfil do solo, tratando-se, contudo, de locais nos quais existiam poucas plantas de macaúba. O maior número de plantas foi observado em solos pouco intemperizados, ricos em minerais, como muscovita, com vários afloramentos de micaxistos, pegmatitos e pontuações de feldspato. Nestas áreas, houve predomínio dos Neossolos litólicos e regolíticos e de cambissolos, em detrimento às outras classes de solos. Das dez áreas estudadas, sete estavam sob neossolos, embora com grande variação deste tipo de solo, ocorrendo "manchas" de outras classes.

De acordo com os dados de matiz, valor e croma obtidos, os solos das áreas 6 e 8 apresentaram coloração vermelha, a qual, segundo Freire (2006), está relacionada a óxidos de ferro desidratado (hematita), embora dióxido de manganês e óxidos de ferro parcialmente hidratados também contribuam para esta coloração. As áreas 1, 2, 5 e 10 apresentaram iguais contribuições das cores vermelha e amarela, na formação do matiz do solo. Já nas áreas 3, 4, 7 e 9, houve maior contribuição da cor amarela, na formação do matiz do solo, a qual é devida, principalmente, a óxidos férricos hidratados (goethita).

As médias de cobre solúvel encontradas para oito áreas estudadas (Tabela 4) variaram de $0,1 \mathrm{mg} \mathrm{dm}^{-3} \mathrm{a} 0,3 \mathrm{mg} \mathrm{dm}^{-3}$, teores interpretados como baixos, enquanto, na área 7, havia alto teor, e, na área 6 , médio teor (Sousa \& Lobato 2004). Estes valores médios estão abaixo da média obtida por Naves (1999), de 1,14 $\mathrm{mg} \mathrm{dm}^{-3}$, à profundidade de 0-20 cm, em áreas de Cerrado.

Para o ferro (Tabela 4), foram encontrados valores médios no intervalo de $32,2 \mathrm{mg} \mathrm{dm}^{-3} \mathrm{a}$ 203,6 $\mathrm{mg} \mathrm{dm}^{-3}$, com média de $102 \mathrm{mg} \mathrm{dm}^{-3}$, acima da relatada por Naves (1999), de 55,79 $\mathrm{mg} \mathrm{dm}^{-3}$, em solos de Cerrado típico. Para a maioria das culturas, a disponibilidade adequada situa-se entre $19 \mathrm{mg} \mathrm{dm}^{-3}$ e $30 \mathrm{mg} \mathrm{dm}^{-3}$ (Alvarez Venegas et al. 1999). Nestas condições, somente a área 7 encontrou-se com teor médio deste nutriente próximo a esta faixa.

Considerando-se o nível crítico para o manganês de 5,0 $\mathrm{mg} \mathrm{dm}^{-3}$ (CFSEGO 1988, Sousa \& Lobato 2004), verificou-se que todas as áreas apresentaram resultados bem acima deste nível (Tabela 4). Já para os teores de zinco, nas áreas 3 e 5, estes situaram-se abaixo do nível crítico $\left(1,0 \mathrm{mg} \mathrm{dm}^{-3}\right)$. Outras três áreas $(4,6$ e 7) apresentaram teores médios e as áreas 1, 2, 8, 9 e 10 teores altos (Sousa \& Lobato 2004). 
Tabela 4. Valores da análise química do solo, na camada 0-20 cm, em áreas de ocorrência natural de macaúba, nas regiões centro e sul do Estado de Goiás (2007).

\begin{tabular}{|c|c|c|c|c|c|c|c|c|c|c|c|c|c|c|}
\hline \multirow{2}{*}{ Área* } & $\mathrm{Cu}^{* *}$ & $\mathrm{Fe}^{* *}$ & $\mathrm{Mn}^{* *}$ & $\mathrm{Zn} * *$ & M.O. & \multirow{2}{*}{$\begin{array}{c}\mathrm{pH} \\
\mathrm{CaCl}_{2}\end{array}$} & $\mathrm{P}^{* *}$ & $\mathrm{~K}^{* *}$ & $\mathrm{Ca}$ & $\mathrm{Mg}$ & CTC & $\mathrm{V}$ & $\mathrm{Al}$ & $\mathrm{H}+\mathrm{Al}$ \\
\hline & \multicolumn{4}{|c|}{$\mathrm{mg} \mathrm{dm}^{-3}$} & $\%$ & & \multicolumn{2}{|c|}{$-\mathrm{mg} \mathrm{dm}^{-3}-$} & \multicolumn{3}{|c|}{$-\mathrm{cmol}_{\mathrm{c}} \mathrm{dm}^{-3}-$} & $\%$ & \multicolumn{2}{|c|}{$-\mathrm{cmol}_{\mathrm{c}} \mathrm{dm}^{-3}-$} \\
\hline 1 & 0,2 & 128,7 & 83,5 & 3,2 & 2,9 & 5,1 & 0,8 & 57 & 4,8 & 0,7 & 9,5 & 59,1 & 0,0 & 3,9 \\
\hline 2 & 0,3 & 137,0 & 47,8 & 2,3 & 2,8 & 5,1 & 0,8 & 68 & 3,3 & 1,0 & 8,0 & 56,1 & 0,0 & 3,5 \\
\hline 3 & 0,1 & 147,2 & 37,3 & 0,5 & 1,4 & 4,2 & 1,7 & 57 & 0,3 & 0,2 & 4,5 & 14,2 & 0,8 & 3,9 \\
\hline 4 & 0,2 & 203,6 & 73,9 & 1,1 & 3,8 & 4,7 & 1,4 & 74 & 5,4 & 1,0 & 10,9 & 60,5 & 0,1 & 4,3 \\
\hline 5 & 0,1 & 100,7 & 8,1 & 0,3 & 2,4 & 4,7 & 1,4 & 65 & 2,1 & 0,4 & 7,0 & 38,3 & 0,4 & 4,3 \\
\hline 6 & 0,1 & 77,0 & 49,9 & 1,4 & 2,8 & 5,1 & 1,4 & 76 & 3,0 & 1,1 & 7,1 & 60,5 & 0,0 & 2,8 \\
\hline 7 & 1,8 & 32,2 & 38,8 & 1,2 & 1,9 & 6,7 & 10,2 & 62 & 5,3 & 0,3 & 7,3 & 79,3 & 0,0 & 1,5 \\
\hline 8 & 0,6 & 41,3 & 32,7 & 2,4 & 2,3 & 5,7 & 1,7 & 72 & 3,6 & 0,6 & 6,5 & 67,6 & 0,0 & 2,1 \\
\hline 9 & 0,3 & 109,8 & 102,3 & 1,7 & 3,3 & 5,0 & 1,1 & 55 & 5,1 & 0,8 & 9,5 & 63,3 & 0,0 & 3,5 \\
\hline 10 & 0,3 & 42,4 & 76,0 & 4,7 & 3,4 & 5,7 & 3,5 & 100,6 & 6,2 & 0,8 & 9,8 & 74,4 & 0,0 & 2,5 \\
\hline Média & 0,4 & 102,0 & 55,0 & 1,9 & 2,7 & 5,2 & 2,4 & 68,7 & 3,9 & 0,7 & 8,0 & 57,3 & 0,1 & 3,2 \\
\hline CV(\%) & 128,6 & 53,8 & 51,4 & 70,6 & 26,8 & 13,3 & 118,5 & 19,6 & 46,1 & 45,0 & 23,9 & 32,7 & 205,3 & 29,8 \\
\hline
\end{tabular}

* 1- Santa Cruz de Goiás; 2 - São Miguel do Passa Quatro; 3 - São Francisco de Goiás; 4, 5, 6 e 9 - Jaraguá; 7 - Paraúna; 8 - Jandaia; 10 - Indiara. ** Extraídos pelo método de Mehlich I.

Considerando-se a textura do solo, nas áreas 3 e 7, observou-se baixo teor de matéria orgânica (Tabela 4). As demais áreas apresentaram teor entre adequado e alto, para textura média, e valores considerados médios e adequados, para solos com textura argilosa (Sousa \& Lobato 2004). Sendo assim, as áreas 1,8 e 9 estavam com matéria orgânica em teor adequado e as áreas 2, 5 e 6 em teor médio, enquanto, nas áreas 4 e 10, observou-se teor alto (Tabela 4).

Analisando-se os valores de $\mathrm{pH}$, as áreas 3, 4 e 5 foram classificadas como fortemente ácidas, com $\mathrm{pH}$ inferior a 5,0, à profundidade de $0-20 \mathrm{~cm}$ (CFSEGO 1988). As áreas 1, 2, 6 e 9 apresentaram-se medianamente ácidas ( $\mathrm{pH}$ de 5,0 a 5,5), enquanto as áreas 7,8 e 10 caracterizaram-se como fracamente ácidas (pH de 5,6 a 6,9). Estes valores estão próximos àqueles obtidos por Lopes (1983), para solos de uma vasta área da região dos Cerrados.

Os teores de fósforo (Tabela 4) foram considerados muito baixos, sendo que somente a área 7 apresentou-o em nível adequado (Sousa \& Lobato 2004). O potássio foi identificado em todas as áreas, em altos níveis (CFSEGO 1988).

Nas áreas com teores de argila acima de $40 \%$ (áreas 2 e 6), os valores de cálcio foram considerados médios. Nas demais áreas, cujo teor de argila variou de $20 \%$ a $40 \%$, a maioria (áreas $1,4,7,8,9$ e 10) apresentou altos teores, ao passo que a área 5 apresentou teor médio e a área 3 teor baixo (CFSEGO 1988). Segundo Sousa \& Lobato (2004), teores abaixo de
$1,5 \mathrm{cmol}_{\mathrm{c}} \mathrm{dm}^{-3}$ são considerados baixos, enquadrando-se, nesta situação, somente a área 3. Já níveis entre $1,5 \mathrm{cmol}_{\mathrm{c}} \mathrm{dm}^{-3} \mathrm{e} 7,0 \mathrm{cmol}_{\mathrm{c}} \mathrm{dm}^{-3}$ são interpretados como adequados, enquadrando-se, nestes, todas as demais áreas em estudo.

Solos com teor de argila acima de $40 \%$ apresentaram teores de magnésio considerados médios. Para solos com $20-40 \%$ de argila, os teores foram considerados médios, nas áreas 3, 5, 7 e 8, e altos, nas áreas 1, 4, 9 e 10 (CFSEGO 1988). Naves (1999) obteve valores entre $0,10 \mathrm{cmol}_{c} \mathrm{dm}^{-3}$ e $0,85 \mathrm{cmol}_{\mathrm{c}} \mathrm{dm}^{-3}$, com média de $0,28 \mathrm{cmol}_{\mathrm{c}} \mathrm{dm}^{-3}$, semelhante à variação obtida nas áreas com macaúba, de $0,2 \mathrm{cmol}_{\mathrm{c}} \mathrm{dm}^{-3}$ a $1,1 \mathrm{cmol}_{\mathrm{c}} \mathrm{dm}^{-3}$ (Tabela 4). Segundo Sousa \& Lobato (2004), teores abaixo de $0,5 \mathrm{cmol}_{\mathrm{c}} \mathrm{dm}^{-3}$ são considerados baixos, enquadrando-se, nesta situação, as áreas 3, 5 e 7. Já níveis entre $0,5 \mathrm{cmol}_{\mathrm{c}} \mathrm{dm}^{-3}$ e $2,0 \mathrm{cmol}_{\mathrm{c}} \mathrm{dm}^{-3}$ são interpretados como adequados, nos quais enquadram-se as demais áreas em estudo.

Os resultados de CTC obtidos para os solos com textura argilosa foram caracterizados como baixos, médios e adequados. Para os solos com textura média, obteve-se CTC com níveis baixos, adequados e altos, segundo classificação de Sousa \& Lobato (2004). Valores baixos de CTC indicam alto grau de intemperização destes solos, com predominância de argilas de baixa atividade (Lopes 1983).

A maioria dos solos apresentou saturação de bases acima de 50\% (Tabela 4). Os valores médios da 
saturação encontrados por Motta et al. (2002) foram maiores na presença de macaúba, em Minas Gerais, com mínimo de $17 \%$, máximo de $87 \%$ e média de $57 \%$. Estes aspectos revelam maior fertilidade natural nos solos onde a espécie ocorre, em comparação aos solos adjacentes, sem tal ocorrência.

A saturação de bases foi considerada alta, nas áreas 1 e 2, e muito alta, nas áreas 4, 6, 7, 8, 9 e 10 , com exceção da área 3 , cuja saturação de bases mostrou-se baixa, e da área 5, na qual foi considerada média (CFSEGO 1988). Verifica-se que os solos da maioria das áreas estão enquadrados, quanto à saturação por bases, como solos eutróficos, isto é, com mais de $50 \%$ de saturação por bases, característicos como solos de fertilidade alta.

Segundo Motta et al. (2002), a distribuição da macaúba, em Minas Gerais, refletiu-se na preferência por solos eutróficos, em detrimento de solos álicos. Rocha (1946) e Lorenzi (1992) também salientaram a preferência da macaúba por solos férteis, enquanto Novaes (1952), ao contrário, afirma ser a palmeira adaptada a solos pobres, cobertos por Cerrados, no Estado de São Paulo.

Quanto à presença de alumínio no solo, somente em três áreas este foi detectado, sendo, na área 3, considerado de teor médio, e, nas áreas 4 e 5, baixo, de acordo com a classificação de Tomé Júnior (1997).

Os solos das diferentes áreas de ocorrência da macaúba apresentaram características que, de certa forma, caracterizam estes ambientes, e com variações pouco expressivas entre si. É importante enfatizar que as áreas de estudo são ambientes com forte ação antrópica, visto que muitas delas já haviam passado pela ação de preparo de solo e adubação. $\mathrm{O}$ que se procura é caracterizar o ambiente de ocorrência natural destas palmeiras e verificar a existência de comportamento padrão e definido para determinado conjunto de variáveis do solo. Assim, o conhecimento obtido neste trabalho poderá servir de base para estudos futuros, com o propósito técnico de contribuir para melhor desempenho desta espécie, especialmente diante da possibilidade de esta vir a ser cultivada comercialmente.

\section{CONCLUSÕES}

1. A espécie Acrocomia aculeata foi identificada, predominantemente, em solos com médio a alto nível de fertilidade.
2. Populações de macaúbas foram observadas, predominantemente, em solos do tipo cambissolo e neossolo e de textura média ou franco argilo-arenosa, nas porções declive convexo, tálus e declive côncavo da topossequência.

3. Constatou-se que a macaúba se desenvolve em solos com saturação de bases acima de $50 \%$ e altos níveis de potássio, e que suas populações ocorrem em áreas com precipitação total anual de 1.300-1.700 $\mathrm{mm}$ e temperatura média do ar anual corrigida entre $21,5^{\circ} \mathrm{C}$ e $22,5^{\circ} \mathrm{C}$.

\section{AGRADECIMENTOS}

Ao Conselho Nacional de Desenvolvimento Científico e Tecnológico (CNPq), pela bolsa concedida ao primeiro autor.

\section{REFERÊNCIAS}

ALVAREZ VENEGAS, V. H. et al. Interpretação dos resultados das análises de solos. In: RIBEIRO, A. C.; GUIMARÃES, P. T. G.; ALVAREZ VENEGAS, V. H. (Eds.). Recomendações para o uso de corretivos e fertilizantes em Minas Gerais: $5^{\text {a }}$ aproximação. Viçosa: CFSEMG, 1999. p. 25-32.

ARISTONE, F.; OLIVEIRA, T. C. M. Exploração autosustentável da bocaiúva na região do Pantanal SulMatogrossense: geração de renda e equilíbrio do meio ambiente. Universidade Federal de Mato Grosso do Sul, 2004.

COMISSÃO DE FERTILIDADE DE SOLOS DO ESTADO DE GOIÁS (CFSEGO). Recomendação de corretivos e fertilizantes para Goiás: $5^{\mathrm{a}}$ aproximação. Goiânia: UFG/Emgopa, 1988.

EMPRESA BRASILEIRA DE PESQUISA AGROPECUÁRIA (Embrapa). Manual de métodos de análise de solo. 2. ed. Rio de Janeiro: Embrapa, 1997.

EMPRESA BRASILEIRA DE PESQUISA AGROPECUÁRIA (Embrapa). Centro Nacional de Pesquisa de Solos. Sistema brasileiro de classificação de solos. Rio de Janeiro: Embrapa, 1999.

FREIRE, O. Solos das regiões tropicais. Botucatu: Fepaf, 2006.

HENDERSON, A.; GALEANO, G.; BERNAL, R. Field guide to the palms of the Americas. New Jersey: Princeton University Press, 1995. 
LOBATO, E. J. V. et al. Atlas climatológico do Estado de Goiás. Goiânia: Ed. da UFG, 2002.

LOPES, A. S. Solos sob "Cerrado": características, propriedades e manejo. Piracicaba: Potafos, 1983.

LORENZI, H. Árvores brasileiras: manual de identificação e cultivo de plantas arbóreas nativas do Brasil. Nova Odessa: Plantarum, 1992.

MARKLEY, K. S. Mobocayá or Paraguay coco palm: an important source of oil. Economic Botany, New York, v. 10, n. 1, p. 3-32, 1956.

MOTTA, P. E. F. et al. Ocorrência da macaúba em Minas Gerais: relação com atributos climáticos, pedológicos e vegetacionais. Pesquisa Agropecuária Brasileira, Brasília, DF, v. 37, n. 7, p. 1023-1031, 2002.

NAVES, R. V. Espécies frutíferas nativas dos Cerrados de Goiás: caracterização e influências do clima e dos solos. 1999. 206 f. Tese (Doutorado em Agronomia)-Escola de Agronomia, Universidade Federal de Goiás, Goiânia, 1999.

NOVAES, R. F. Contribuição para o estudo do coco macaúba. 1952. 85 f. Tese (Doutorado em Ciências Agrárias)-Escola Superior de Agricultura "Luiz de Queiroz”, Universidade de São Paulo, Piracicaba, 1952.

NUCCI, S. M. Desenvolvimento, caracterização e análise da utilidade de marcadores microssatélites em genética de população de macaúba. 2007. 90 f. Dissertação (Mestrado em Agricultura Tropical e Subtropical)Instituto Agronômico de Campinas, Campinas, 2007.
PEREIRA, B. A. S. Flora nativa. In: DIAS, B. F. S. (Coord.). Alternativas de desenvolvimento dos Cerrados: manejo e conservação dos recursos naturais renováveis. Brasília, DF: Fundação Pró-Natureza, 1996. p. 53-57.

PRATES, J. E.; SEDIYMA, G. C.; VIEIRA, H. A. Clima e produção agrícola. Informe Agropecuário, Belo Horizonte, v. 12, n. 138, p. 18-22, 1986.

ROCHA, O. O coco macaúba. Revista de Agricultura, Piracicaba, v. 21, n. 1, p. 345-358, 1946.

SCARIOT, A.; LLERAS, E.; HAY, J. D. Flowering and fruiting phenologies of the palm Acrocomia aculeata: patterns and consequences. Biotropica, Washington, DC, v. 27, n. 2, p. 168-173, 1995.

SILVA, J. C.; BARRICHELO, L. E. G.; BRITO, J. O. Endocarpos de babaçu e de macaúba comparados à madeira de Eucalyptus grandis para a produção de carvão vegetal. Revista IPEF, Piracicaba, v. 34, n. 1, p. 31-34, 1986.

SOUSA, D. M. G.; LOBATO, E. Cerrado: correção do solo e adubação. 2. ed. Planaltina: Embrapa Cerrados, 2004.

TOMÉ JUNIOR, J. B. Manual para interpretação de análise de solo. Guaíba: Agropecuária, 1997.

WANDECK, F. A.; JUSTO, P. G. A macaúba, fonte energética e insumo industrial: sua significação econômica no Brasil. In: SIMPÓSIO SOBRE O CERRADO, 6., 1988, Brasília, DF. Anais... Planaltina: Embrapa-CPAC, 1988. p. 541-577. 